\title{
Evaluation of the Effect of Systemic Omega-3 Polyunsaturated Fatty Acids on Post-Orthodontic Relapse in a Rabbit Model
}

\author{
Asser $\mathrm{Gad}^{1}$, Essam Abdallah ${ }^{2}$, Nadia ElHarouni $^{3}$, Samia Soliman $^{4}$
}

\section{ABSTRACT:}

Introduction: Long term stability is the major goal of orthodontic treatment. Hence, a series of safe pharmacological agents have been investigated to increase osteoblastic activity around orthodontically moved teet $h$ to help in retention and stability of their correction. Aim of the study: To evaluate the effect of systemic administration of Omega-3 fatty acids on post-orthodontic relapse, and to histologically assess bone changes concurrent with its administration in rab6its. Materials and Methods: Thirty two adult albino male rabbits were divided equally and randomly into two groups. Each group received $\mathcal{N} i \mathrm{Ti}$ coil springs installed on mandibular first molars and ligated to anterior incisors. Omega-3 or Saline were given from day one of orthodontic tooth movement (OTM) till end of relapse period by oral gavage. After 21 days of active OTM, appliances were removed from both groups to allow orthodontic relapse (OR); then amount and percentage of relapse were measuredon days 21, 28 and 42. Animals were sacrificed for histomorphometric analysis of alveolar bone remodeling. Results: A significant difference in relapse percentage was found on the third week of OR with means $(66.04 \pm 6.01 \%)$ and $(75.22 \pm 13.61 \%)$ for experimental and control groups, respectively. Histomorphometric analysis showed a significant reduction in the area of active bone-resorptive lacunae and a significant increase in newly formed bone area related to omega-3 group. Conclusions: $\mathcal{A}$ strong evidence of the osteoblastic simulative effect of Omega-3 had been found with decreased percentage of OR after OTM.

Keywords: Oral gavage, Omega-3, Rab6its, Relapse.

\section{INTRODUCTION}

Any OTM requires a retention phase, which aims to stabilize the tooth elements in its new position and prevent what is called relapse. Yoshida et $\mathrm{al}^{1}$ proposed that remodeling of the periodontal ligament fibers and alveolar bone are the main causes of relapse. In addition, Franzen et $\mathrm{al}^{2}$ found that orthodontic relapse and OTM are associated with similar cellular adaptations, such as increased osteoclastic differentiation in compression areas. Given this background, one could argue that endogenous or pharmacologic bone modulation to inhibit osteoclast resorption and promote osteoblast neoformation may have clinically

\footnotetext{
1- Assistant Lecturer, Orthodontic Department,Faculty of Dentistry, KafrElsheikh University.

2- Professor, Orthodontic Department, Faculty of Dentistry, Alexandria University.

3- Professor, Orthodontic Department, Faculty of Dentistry, Alexandria University.

4- Professor, Oral Biology Department, Faculty of Dentistry, Alexandria University.
} 
relevant effects on the regulation of OTM and relapse. Recently, retention strategies are aimed at increasing alveolar bone density after cessation of orthodontic tooth movement or control of alveolar bone remodeling around tooth roots by influencing osteoblasts and/or osteoclasts activity to prevent tooth relapse.

For nearly four decades, PUSFs family has been studied extensively in relation to prevention and treatment of cardiovascular disease. $^{3}$ The health-promoting effects of omega-3 fatty acids (FAs) may be partially due to their immune-modulating and anti-inflammatory actions. ${ }^{4}$ Although this was first described in cardiovascular disease, the potential role that inflammatory mediators play in metabolic bone diseases such as osteoporosis, has caused investigators to extend studies of n-3 FAs to include skeletal outcomes. ${ }^{5}$ Omega-3 PUFAs are able to modulate inflammation, hyperlipidemia, platelet aggregation, and hypertension. Different mechanisms contribute to these effects, including conditioning cell membrane function and composition, eicosanoid production, and gene expression. ${ }^{6}$ Omega-3 fatty acids are found mainly in fish oil where the major PUFA components are eicosapentaenoic acid (EPA) and docohexaenoic acid (DHA).

Iwami-Morimoto et $\mathrm{al}^{7}$ found that diet containing high omega-3 PUFA ratios decreased experimental tooth movement in rats than that rich in omega-6 FAs. ${ }^{8}$

A recent review declared that $n-3$ and $n-6$ PUFA play a role in bone development and that n-3 PUFA may improve bone health by increasing calcium absorption in the gut, and increasing osteoblast differentiation and activity, reducing osteoclast activity and promoting deposition of mineral in developing bones. ${ }^{9}$

This paucity of information about omega-3 effect in orthodontics indicatedthe need for a more structured research approach, in both animal models and humans, to provide clinicians with more evidence-based results. In this study, we used an experimental rabbit model to explore the effect of systemic administration of omega-3 on post-orthodontic relapse. It was hypothesized that the osteoinductive effects of omega-3 on the dental supporting tissues as well as the inhibition of osteoclastic activity might minimize post-orthodontic relapse in rabbits. The research null hypothesis was that omega-3 supplement has no effect on post-orthodontic relapse.

\section{MATERIAL AND METHODS}

Thirty two adult male New Zealand albino rabbits (12 to 16 weeks old with body weight about 2.8 to $3.2 \mathrm{~kg}$ ) were used for the experiment in the animal house of institute of graduate studies and research, Alexandria University, Egypt. Throughout the whole study period, animals were examined daily by the veterinarian staff for evaluation of the general health status of each animal, weight loss, appliance breakage, gingival or soft tissue inflammation. The animals were maintained at room temperature between $20^{\circ}$ and $25^{\circ} \mathrm{C}$ with constant humidity, fed with standard ground ration and water. All procedures involving animals were in strict accordance with the American Veterinary Medical Association guidelines and approved by the Ethicscommittee of the Faculty of Dentistry, Alexandria University in Egypt, which includes 
the institutional experimentation committee, approved the research protocol.

Calculation of required sample size was performed based on the formula for estimating sample size for studies comparing paired continuous data,

$$
\mathrm{n}=1+2 \mathrm{C}(\mathrm{S} / \mathrm{D})^{2}
$$

Where: $\mathrm{S}$ is the standard deviation, $\mathrm{D}$ is the expected difference to be detected, $C$ is a constant dependent on the value of $\alpha$ and $\beta$ selected. For $\alpha=0.05$ and $1-\beta=0.9, \mathrm{C}$ is 10.51 .

Rabbits were divided into 2 groups, group I (16 animals) served as study (Appliance + Omega-3) and group II as control (Appliance + normal saline). The animals in each group were anaesthetized on the first day by an intramuscular injection of Ketamine (50mg/kg body weight) and Intramuscular injection of diazepam (5mg/kg body weight) for appliance placement ${ }^{10}$. Firstly, grooves were made coronally around the molar and incisors with occlusal reduction on the target molar teeth to eliminate unwanted occlusal forces during tooth movement using airotor handpiece under suction device. Enamel was treated for 20 seconds by BISCO (All bond universal light cured dental adhesive, USA)around the coronal portions of the molars and incisors including grooves. The treated portions were thoroughly isolated with an airway syringe.

After surface preparations, ligature wire (0.09 mm)was passed interdentally between first and second molars and wrapped around the first molar, similarly ligature wire also tied in figure of eight manner around incisors, and twisted with artery forceps till they fit into the grooves, then NiTi coil springs were tied to ligature wire between mandibular molar and incisors with 100 gram force using tensiometer (Morelli Orthodontic Tension Meter Force Gauge Intra/Extra Oral Elastics, Brazil). ${ }^{11,12}$ The excess wires were cut with ligature cutter and the ligature wires were bent closely towards teeth surfaces to avoid injury to soft tissue. Athin coat of flow able composite (Z350 XT flow, 3M ESPE, Calif, USA) was applied and light cured in order to avoid dislodgement of the appliance and lessen irritation of any wire projections. (Fig.1)

A piece of ligature wire was used to ligate the second molar to the third one to prevent any possible movement of the second molar with the mesial movement of the first molar by the effect of the gingival interseptal fibers using the same flowable compsite to secure the wire to the enamel surface and prevent its dislodgment, (Fig.2A)

All rabbits were subjected to OTM for 21 days then allowed for relapse for another 21 days, receiving oral gavage daily (200 mg/kg) of Omega- $3^{13,14}$ or Saline from day one of OTM till end of OR period.

After 21 days of OTM (Fig.2A\&B), rabbits were anaesthetized and removal of orthodontic appliance to allow for OR was done. Impressions (T1) for lower jaws (Fig.2C) and blood samples from auricular vein were taken (Fig.2). On $28^{\text {th }}$ day, another impressions (T2) and blood samples were taken after anaesthetizing rabbits. At the end of OR period (on $42^{\text {th }}$ day), final impressions (T3) and final blood samples were taken, then animals were sacrificed for histological study. 

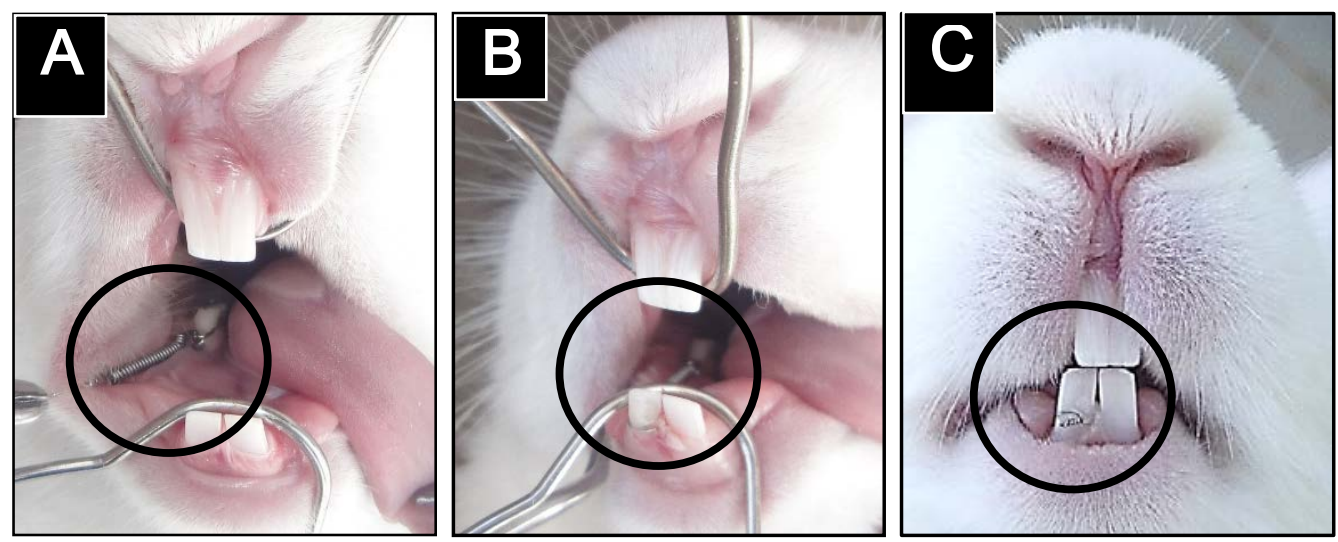

Figure.1. Intraoral photographs showing (a) ligation of coil spring to first molar tooth (b) ligation of coil spring to the incisor and (C) light cure flow able composite application
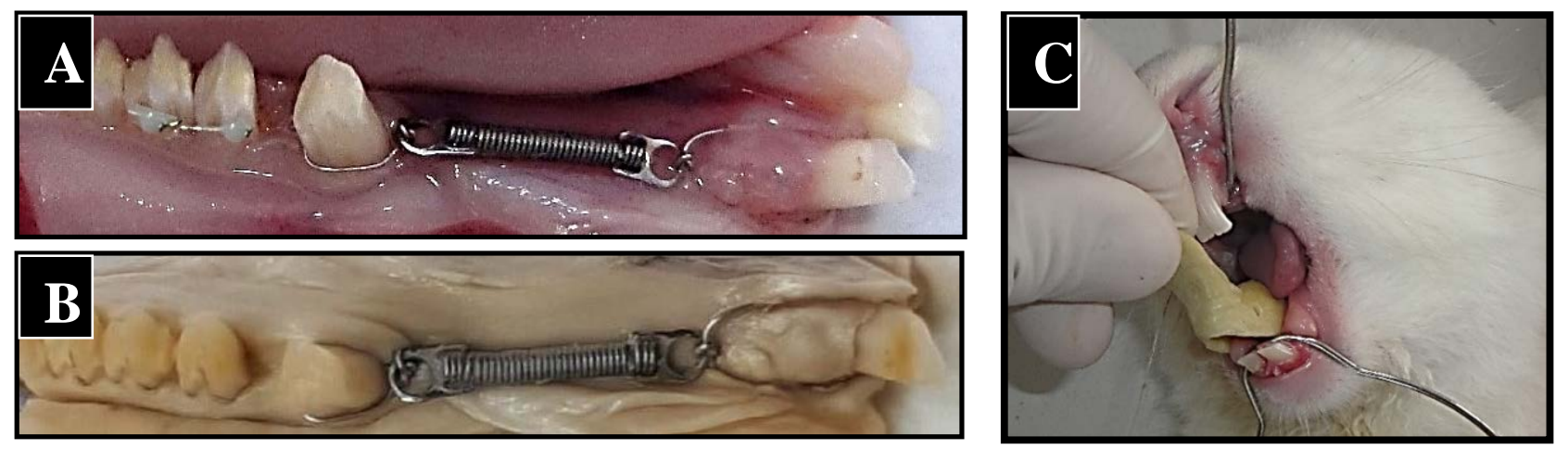

Figure.2A-C. (A\&B) dissected rabbit mandible showing the appliance design and the diastema between molars after 21 days of active orthodontic tooth movement and (C)Impression making with light body Vinyl Polysiloxane and custom made special tray

\section{STATISTICAL ANALYSIS}

In an effort to preserve reliability, all model measurements and analyses were performed by the same investigator. To exclude the intra-examiner error in measurements, 10 models randomly selected were retraced 2 weeks after the first measurements by the same examiner. A paired t-test and intraclass correlation coefficient were performed to the first and second measurements. It was noted that the difference between the two sets of measurements was insignificant, the paired ttest and the intraclass correlation coefficient was greater than 0.9 .

The statistical analysis was accomplished using Statistical Package for Social Sciences
SPSS (version 20) software. The KolmogorovSmirnov test was used to verify the normality of distribution Quantitative data were described using range (minimum and maximum), mean, standard deviation and median. Significance of the obtained results was judged at the 5\% level, differences with P-values less than 0.05 was considered significant.

\section{RESULTS}

\section{Clinical Results:}

After 3 weeks of force application, tooth movement of the first molars ranged from $1.8 \mathrm{~mm}$ to $2.9 \mathrm{~mm}$, with a mean movement of $1.8 \pm 0.41 \mathrm{~mm}$. There were no significant differences in the amount of movement between the two groups. 
After 1 week of relapse, the amount and percentage of relapse in the experimental group $(0.87 \pm 0.20 \mathrm{~mm} ; 45.03 \pm 2.98 \%)$ were nearly the same as the control group $(0.78 \pm 0.20 \mathrm{~mm}$; $45.54 \pm 1.63 \%$ ), without any significant difference.

After 3 weeks of relapse, the amount and percentage of relapse in the experimental group $(1.29 \pm 0.36 \mathrm{~mm} ; 66.04 \pm 6.01 \%)$ were
$(\mathrm{P}<0.001)$ less than the amount and percentage of relapse in the control $(1.17 \pm 0.39 \mathrm{~mm}$; $75.22 \pm 13.61 \%$ ) but the significant difference was found mainly in the percentage of relapse only, as shown in tables (1) and (2).

Blood samples showed significant increase in the serum ALP in experimental group on the $3^{\text {rd }}$ week of OR. (Fig.3)

Table (1): Showing a comparison between the two studied groups according to amount of relapse (mm).t, $\mathrm{p}: \mathrm{t}$ and $\mathrm{p}$ values for Student t-test for comparison between the two groups.*: Statistically significant at $\mathrm{p} \leq 0.05$.

\begin{tabular}{|c|c|c|c|c|}
\hline Change of movement (mm) & $\begin{array}{l}\text { Experimental } \\
\qquad(\mathbf{n}=16)\end{array}$ & $\begin{array}{l}\text { Control } \\
(n=16)\end{array}$ & $\mathbf{t}$ & $\mathbf{p}$ \\
\hline \multicolumn{5}{|l|}{ After one week of relapse } \\
\hline Min. - Max. & $0.59-1.27$ & $0.47-1.14$ & & \\
\hline Mean \pm SD. & $0.87 \pm 0.20$ & $0.78 \pm 0.20$ & 1.260 & 0.218 \\
\hline Median & 0.87 & 0.72 & & \\
\hline \multicolumn{5}{|l|}{ after three weeks of relapse } \\
\hline Min. - Max. & $0.82-2.17$ & $0.83-2.0$ & & \\
\hline Mean \pm SD. & $1.29 \pm 0.36$ & $1.29 \pm 0.39$ & 0.009 & 0.993 \\
\hline Median & 1.31 & 1.17 & & \\
\hline \multicolumn{5}{|l|}{$\begin{array}{l}\text { From } 3^{\text {rd }} \text { week to } 1^{\text {st }} \text { week of } \\
\text { relapse }\end{array}$} \\
\hline Min. - Max. & $0.10-0.90$ & $0.19-1.01$ & & \\
\hline Mean \pm SD & $0.42 \pm 0.22$ & $0.51 \pm 0.26$ & 1.045 & 0.304 \\
\hline Median & 0.37 & 0.47 & & \\
\hline
\end{tabular}

Table (2): Showing a comparison between the two studied groups according to percentage of relapse (mm).t, $\mathrm{p}$ : $\mathrm{t}$ and $\mathrm{p}$ values for Student t-test for comparison between the two groups. *: Statistically significant at $\mathrm{p} \leq 0.05$

\begin{tabular}{|c|c|c|c|c|}
\hline \% of Change of IMD (mm) & Experimental & Control & $\mathbf{t}$ & $\mathbf{p}$ \\
\hline \multicolumn{5}{|l|}{ After one week of relapse } \\
\hline Min. - Max. & $38.55-48.84$ & $43.93-50.89$ & & \\
\hline Mean \pm SD & $45.03 \pm 2.98$ & $45.54 \pm 1.63$ & 0.600 & 0.554 \\
\hline Median & 44.86 & 45.13 & & \\
\hline \multicolumn{5}{|l|}{ After three weeks of relapse } \\
\hline Min. - Max. & $54.29-75.61$ & $56.79-100.0$ & & \\
\hline Mean \pm SD & $66.04 \pm 6.01$ & $75.22 \pm 13.61$ & $2.470^{*}$ & $0.022^{*}$ \\
\hline Median & 65.86 & 72.03 & & \\
\hline \multicolumn{5}{|l|}{ From $3^{\text {nd }}$ week to $1^{\text {st }}$ week } \\
\hline Min. - Max. & $11.11-58.18$ & $22.22-100.0$ & & \\
\hline Mean \pm SD. & $37.65 \pm 13.50$ & $54.38 \pm 24.90$ & $2.362^{*}$ & $0.027^{*}$ \\
\hline Median & 36.02 & 49.20 & & \\
\hline
\end{tabular}




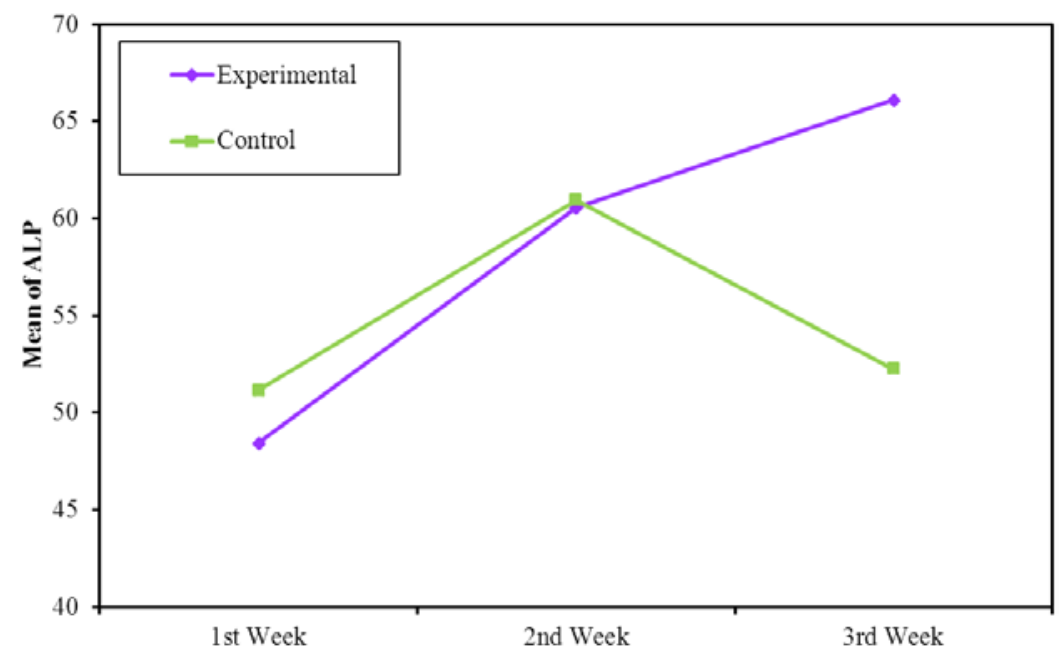

Figure.3. Linear graph Comparing serum alkaline phosphatase between the two studied groups at first, second and third week of relapse

\section{HISTOLOGICAL RESULTS}

Presence of a large number of osteoclasts in the distal surface of the socket was observed in control group with decreased number of osteoblasts in the mesial surface of the socket (Fig.4\&5) which was in contrast with experimental group that showed high osteoblastic activity over osteoclastogenesis, (Fig.6 \&7).

A significant difference was found between experimental and control groups in osteoclast count and the percentage of the area of the newly formed bone on the mesial side, table (3).

Table (3): Showing the significant increase in Osteoclast count in control group and the significant increase in the percentage of the area of the newly formed bone on the mesial side in experimental group.*: Statistically significant at $\mathrm{p} \leq 0.05$

\begin{tabular}{|l|c|c|c|c||}
\hline \multicolumn{1}{|c|}{ Parameter } & Experimental & Control & Test of sig & P \\
\hline \hline Osteoclast Count & $2.33= \pm 0.98$ & $4.33 \pm 0.49$ & 2.14 & $0.0008^{*}$ \\
\hline \hline Newly formed bone area & $75.58 \pm 6.65$ & $59.05 \pm 10.49$ & 2.14 & $0.00018^{*}$ \\
\hline
\end{tabular}
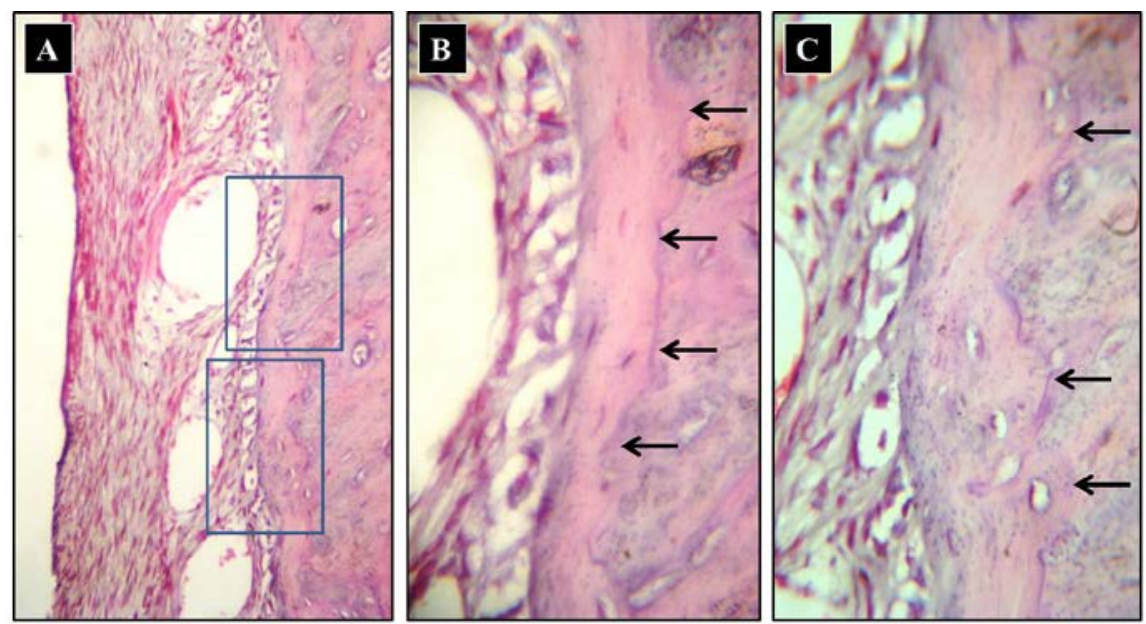

Figure.4A-C. Light micrograph (LMs) from mesial surface of control group (relapse tension) showing: (A) Organization of the PDL, its width and fiber tension. [H\&E stain, X100], and (B\&C) Higher magnification revealing the deposited bone on the border of socket and the adjacent reversal lines of previous bone resorption (arrows). [H\&E stain, X400]. 


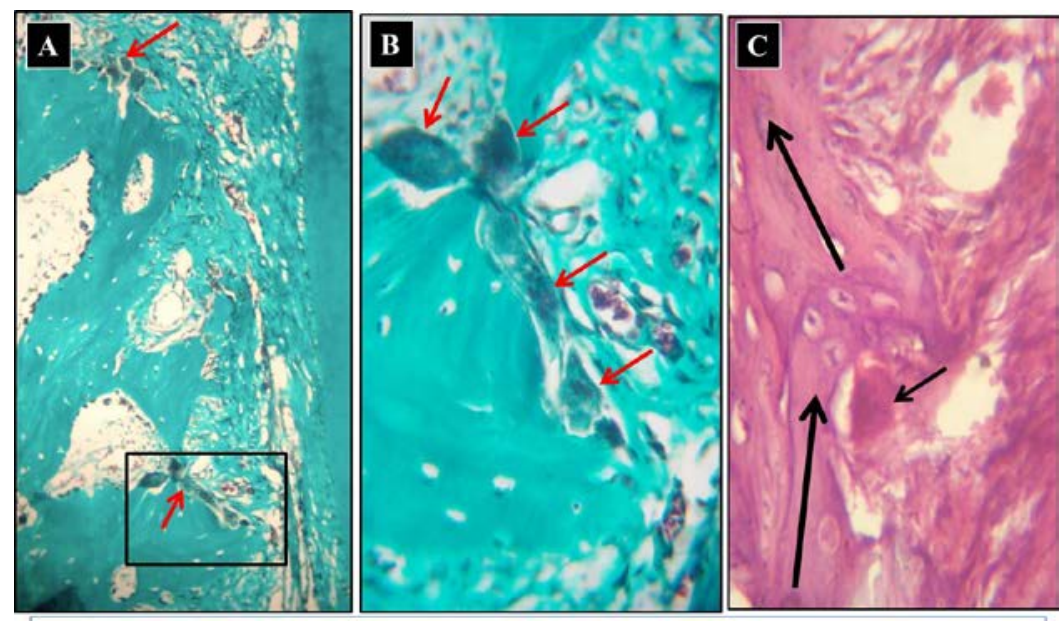

Figure.5A-C. Light micrograph (LMs) from distal surface of control group (relapse compression) showing: (A)The irregular surface of the alveolar bone $(\mathrm{AB})$ boundary and the voluminous osteoclasts [Trichrome stain, $\mathrm{X} 100]$, and (B\&C) Magnification of the boxed area in (A) revealing the volume \& organization of osteoclasts [Trichrome stain , X400], while (C) showing the persistence of unresorbed bone segments (arrows) on the alveolar surface [H\&A, X400].

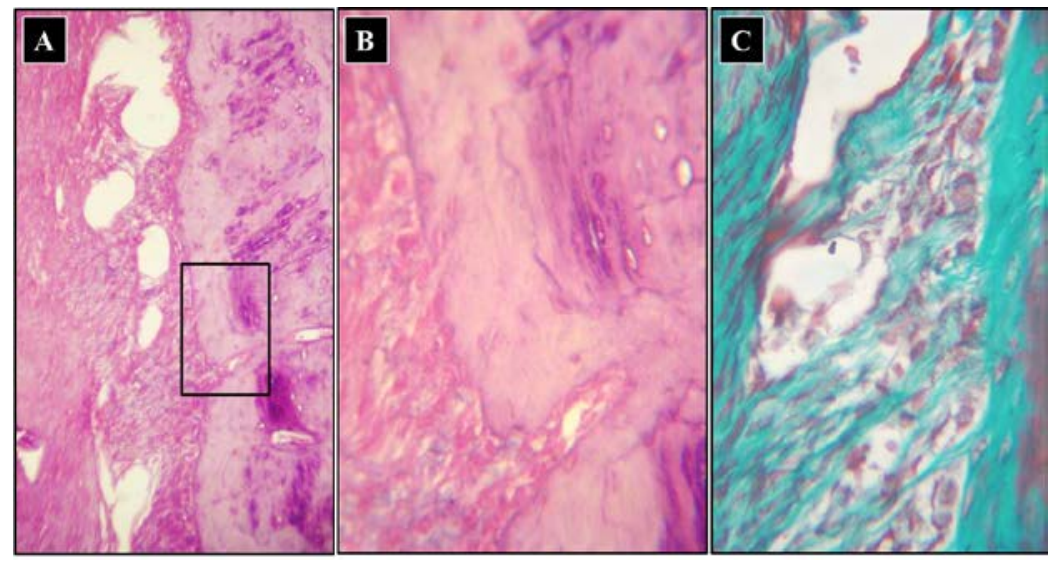

Figure.6A-C. Light micrograph (LMs) from mesial surface of study group (relapse tension) showing: (A) marked amount of bone deposition adjacent to PDL. [H\&E stain, X100], (B\&C) magnification of the boxed area in $(\mathrm{A})$ revealing the extent of deposited bone on the border of socket and the adjacent reversal lines of previous bone resorption, [B: H\&E stain, X400], marked osteoblastic activity and organization adjacent to the formed bone, [C: Trichrome stain, X400].

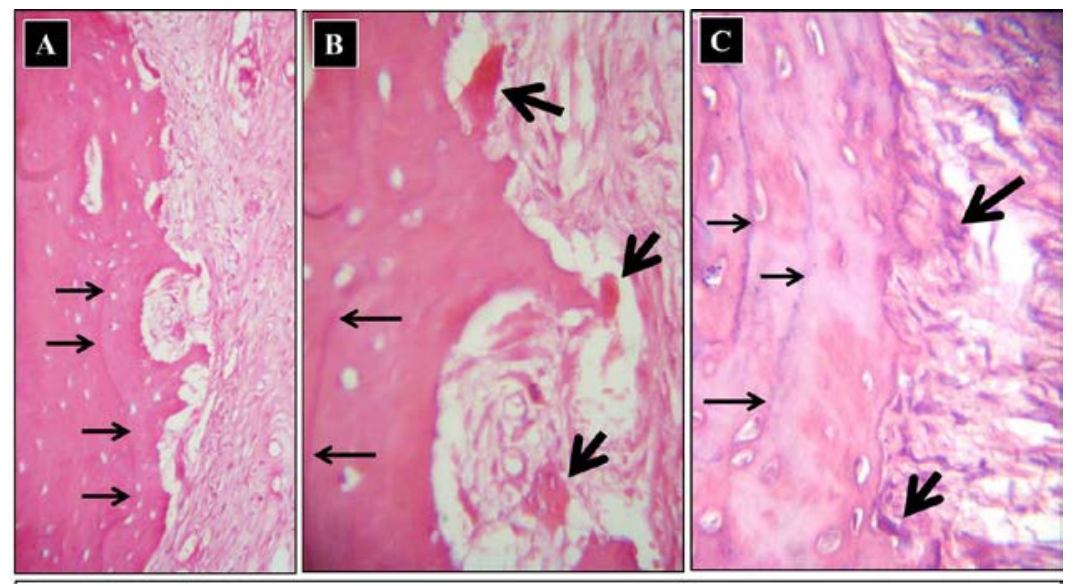

Figure.7A-C. Light micrograph from distal surface of study group (relapse compression) showing: (A) the persistence of the previously formed bone delineated by resting lines (thin arrows). [H\&E stain, X100], and (B\&C) evidence of shallow resorption bays in association with small osteoclasts.[H\&E stain, X400]. 


\section{DISCUSSION}

Omega-3 PUFAs are essential to normal growth and health. Recently, a strong relation was found between these acids, bone health and bone formation. The former was found to affectbone formation, bone resorption, serum calcium and inflammatory mediators, but the exact mechanism of action has not yet been determined. ${ }^{15}$

The rabbit is one of the most widely used models for studying bone remodeling. In the current study, the rabbit model was chosen, in comparison with other species, such as primates and some rodents, as rabbits have faster skeletal change and bone turnover (significant intracortical, Haversian remodeling). ${ }^{16,17}$

The spring design and the active toothmovement period of 21 days were chosen in this studyin accordance with other studies with rabbits. $^{10,11,18,19}$

The intermolar distancewas measured with a digital caliper on stone casts because it was believed that it would be repeatable, easier and more accurate than doing it directly while the animal was under anesthesia.

In agreement with other authors, we found a greater relapse rate in both groups immediately after appliance removal, which gradually decreased up to 21 days. ${ }^{1,20}$

In the first week of relapse, almost half of the total distance was in relapse in both groups (experimental group $45.03 \pm 2.98 \%$ and control group $45.54 \pm 1.63 \%)$. A significant decrease of ORwas found in the experimental group rather than in the control group after three weeks of relapse. This delay of action was due to oral gavage administration which was in agreement with Azuma et $\mathrm{al}^{21}$ and Al-Hashimi et $\mathrm{al}^{14}$.

Histologically, the appearance of the osteoblasts in experimental group either on the mesial or distal surface of the socket was noticeably greater than their appearance in control group. On the other hand, osteoclasts were noticeable smaller, less frequently encountered and less active than those observed on the same surface of the control teeth. Iwami-Morimoto et al ${ }^{7}$ showed that fish oil enriched diets reduced osteoclastic activity and the amount of alveolar bone resorption on the pressure side which was in agreement with our study and other studies in mice ${ }^{22}$, rats ${ }^{13}$ and humans ${ }^{23}$.

In addition, all previous studies that had examined the effect of dietary lipids on alveolar bone remodeling or orthodontic tooth movement, are consistent with our study results about the inhibitory effect of omega-3 on alveolar bone resorption. Alam et $\mathrm{al}^{24}$ found a relation between the type of dietary lipids and the fatty acid composition of bone lipids. Kokkinos et $\mathrm{al}^{25}$ revealed that omega-3 enriched diet had inhibitory effect on OTM. Both studies concluded lipid diets induced changes in archidonic acid level in alveolar bone with accompanied changes in PG levels. Moreover, our study used oral gavage to deliver and assure the intake of proper amounts of omega-3 supplement.

In addition, increased serum ALPin experimental group after three weeks of relapse confirmed the high osteoblastic activity of omega-3 fatty acids as serum ALP considered as one of the bone markers related to osteoblastic activity in bone formation. ${ }^{26}$ The present study results were in agreement with other studies. ${ }^{27-29}$

The current study revealed that osteoclast count and orthodontic relapse are directly correlated, highlighting the importance of bone resorption during the relapse phase. This was in 
agreement with the study done by Dolci et $\mathrm{al}^{30}$ who concluded that Statin-induced OPG overexpression reduced relapse after OTM, in a phenomenon correlated with decreased osteoclast counts. However, considering overall osteoclast number and relapse findings, we observed that the control group hadhigh relapse rates and osteoclast counts, whereas the omega-3group exhibited the opposite profile.

\section{CONCLUSION}

The results of the present study indicate that systemic administration of omega-3 PUFAs could reduce the amount of orthodontic tooth relapsedue to its osteoblastic stimulatory effect.

\section{REFERENCE}

1. Yoshida Y, Sasaki T, Yokoya K, Hiraide T, Shibasaki Y. Cellular roles in relapse processes of experimentally-moved rat molars. J Electron Microsc (Tokyo) 1999;48:147-157.

2. Franzen TJ, Monjo M, Rubert M, VandevskaRadunovic V. Expression of bone markers and micro-CT analysis of alveolar bone during orthodontic relapse. Orthod Craniofac Res 2014;17:249-258.

3. Block RC, Harris WS, Reid KJ, Sands SA, Spertus JA. EPA and DHA in blood cell membranes from acute coronary syndrome patients and controls. Atherosclerosis 2008;197: 821-828.

4. Dawczynski C, Schubert R, Hein G, Muller A, Eidner $\mathrm{T}$, Vogelsang $\mathrm{H}$ et al. Long-term moderate intervention with $\mathrm{n}-3$ long-chain PUFA-supplemented dairy products: effects on pathophysiological biomarkers in patients with rheumatoid arthritis. Br J Nutr 2009;101: 1517-1526.

5. Ding C, Parameswaran V, Udayan R, Burgess J, Jones G. Circulating levels of inflammatory markers predict change in bone mineral density and resorption in older adults: a longitudinal study. J Clin Endocrinol Metab 2008;93: 1952-1958.
6. Molfino A, Gioia G, Rossi Fanelli F, Muscaritoli M. The role for dietary omega-3 fatty acids supplementation in older adults. Nutrients 2014;6:4058-4073.

7. Iwami-Morimoto $\mathrm{Y}$, Yamaguchi K, Tanne K. Influence of dietary n-3 polyunsaturated fatty acid on experimental tooth movement in rats. Angle Orthod 1999;69:365-371.

8. van der Merwe CF. A different and physiological approach to manipulating the inflammatory response. European Journal of Gastroenterology \& Hepatology 1993;5:433-436.

9. Lau BY, Cohen DJ, Ward WE, Ma DW. Investigating the role of polyunsaturated fatty acids in bone development using animal models. Molecules 2013;18:14203-14227.

10. Venkataramana V, Kumar SS, Reddy BV, Cherukuri AS, Sigamani KR, Chandrasekhar G. Administration of bisphosphonate (ibandronate) impedes molar tooth movement in rabbits: A radiographic assessment. J Pharm Bioallied Sci 2014;6:S165-170.

11. Venkataramana V, Chidambaram S, Reddy BV, Goud EV, Arafath M, Krishnan S. Impact of Bisphosphonate on Orthodontic tooth movement and osteoclastic count: An Animal Study. J Int Oral Health 2014;6:1-8.

12. Venkataramana V, Rajasigamani K, Nirmal M, Reddy SN, Karthik K, KurunjiKumaran N. Inhibitory Effect of Bisphosphonate on orthodontic tooth movement in newzeland albino rabbits. J Int Dent Med Res 2012;5:136-142.

13. Sakaguchi K, Morita I, Murota S. Eicosapentaenoic acid inhibits bone loss due to ovariectomy in rats. Prostaglandins Leukot Essent Fatty Acids 1994;50:81-84.

14. Al-Hashemi H, Al-Khashab E, Hamdoon A. Effect of high doses of omega-3 fatty acids on the Metabolism of bones in adult females rats. Raf. J. Sci 2013;24:17-26.

15. Azemati M, Shakerhosseini R, Hekmatdos A, Alavi-Majd H, Hedayati M, Houshiarrad A et al. Comparison of the effects of canola oil versus sunflower oil on the biochemical markers of bone metabolism in osteoporosis. 
Journal of Research in Medical Sciences : The Official Journal of Isfahan University of Medical Sciences 2012;17:1137-1143.

16. Castaneda S, Largo R, Calvo E, RodriguezSalvanes F, Marcos ME, Diaz-Curiel $\mathrm{M}$ et al. Bone mineral measurements of subchondral and trabecular bone in healthy and osteoporotic rabbits. Skeletal Radiol 2006;35:34-41.

17. Newman E, Turner AS, Wark JD. The potential of sheep for the study of osteopenia: current status and comparison with other animal models. Bone 1995;16:277S-284S.

18. Roche JJ, Cisneros GJ, Acs G. The effect of acetaminophen on tooth movement in rabbits. Angle Orthod 1997;67:231-236.

19. Yu JY, Lee W, Park JH, Bayome M, Kim Y, Kook YA. Histologic effects of intentionalsocket-assisted orthodontic movement in rabbits. Korean J Orthod 2012;42:207-217.

20. Franzen TJ, Brudvik P, Vandevska-Radunovic V. Periodontal tissue reaction during orthodontic relapse in rat molars. Eur J Orthod 2013;35: 152-159.

21. Azuma MM, Gomes-Filho JE, Ervolino E, Pipa CB, Cardoso CdBM, Andrada AC et al. Omega 3 Fatty Acids Reduce Bone Resorption While Promoting Bone Generation in Rat Apical Periodontitis. Journal of Endodontics 2017;43:970-976.

22. Sun D, Krishnan A, Zaman K, Lawrence R, Bhattacharya A, Fernandes G. Dietary n-3 fatty acids decrease osteoclastogenesis and loss of bone mass in ovariectomized mice. J Bone Miner Res 2003;18:1206-1216.
23. Kruger MC, Horrobin DF. Calcium metabolism, osteoporosis and essential fatty acids: a review. Prog Lipid Res 1997;36:131-151.

24. Alam SQ, Kokkinos PP, Alam BS. Fatty acid composition and arachidonic acid concentrations in alveolar bone of rats fed diets with different lipids. Calcif Tissue Int 1993;53:330-332.

25. Kokkinos PP, Shaye R, Alam BS, Alam SQ. Dietary lipids, prostaglandin E2 levels, and tooth movement in alveolar bone of rats. Calcif Tissue Int 1993;53:333-337.

26. Leung KS, Fung KP, Liu PP, Lee KM. Bone-specific alkaline phosphatase activities in plasma and callus during callotasis in rabbits. Life Sci 1995;57:637-643.

27. Watkins BA, Li Y, Lippman HE, Feng S. Modulatory effect of omega-3 polyunsaturated fatty acids on osteoblast function and bone metabolism. Prostaglandins Leukot Essent Fatty Acids 2003;68:387-398.

28. Watkins BA, Li Y, Lippman HE, Seifert MF. Omega-3 polyunsaturated fatty acids and skeletal health. Exp Biol Med (Maywood) 2001;226:485-497.

29. Watkins BA, Lippman HE, Le Bouteiller L, Li Y, Seifert MF. Bioactive fatty acids: role in bone biology and bone cell function. Progress in Lipid Research 2001;40:125-148.

30. Dolci GS, Portela LV, Onofre de Souza D, Medeiros Fossati AC. Atorvastatin-induced osteoclast inhibition reduces orthodontic relapse. Am J Orthod Dentofacial Orthop 2017;151:528-538. 